\title{
Researching Innovations in English Language Writing Instruction: A State-of-the-art Review
}

\author{
Weiyu Zhang \\ Department of English, Shenzhen Open University, China \\ Yin Ling Cheung \\ National Institute of Education, Nanyang Technological University, Singapore
}

\begin{abstract}
With academic writing viewed as an important aspect of language instruction, there is an increasing interest on how writing education could be improved to better accommodate the needs of multilingual learners. To evaluate the empirical evidence from published research studies, we conducted a systematic synthesis of the published research that has examined innovations in English-as-a-foreign language writing instruction in China, in contexts including tertiary, secondary, and elementary schools. General claims emerged across our analyses of 56 empirical studies published in the SSCI journals in English from 2005-2015. Each claim is supported by empirical evidence: (1) corpus-based approaches are useful in analyzing students' writing; (2) students' affective and cognitive factors may influence the outcome of writing instruction; (3) training may help teachers improve confidence in teaching writing; (4) differences may appear between assessment-oriented teacher feedback and non-assessment-oriented teacher feedback; (5) assessment for learning influences student learning of writing; (6) instruction may help writers acquire skills and knowledge of writing for publication; (7) technology-enabled instruction can help students in their writing process; and (8) novel and authentic writing tasks can promote students' critical thinking ability.
\end{abstract}

Index Terms —English writing education, innovations, multilingual learners

\section{INTRODUCTION}

This review paper aims to provide a synthesis of recent research documenting innovations in English language writing education that took place from 2005-2015 in China. Efforts of innovations could be observed at all levels (i.e., primary, secondary and tertiary) concerning the area of academic writing, with important implications on how to improve the quality and outcome of English language instruction (Gao, Liao, \& $\mathrm{Li}$; $\mathrm{Hu}, 2005$ ) in the multilingual context. In China, English is used as a foreign language. Students generally receive formal instruction in English from age 11-12. Teachers have been adopting a product-oriented approach in teaching English language writing because of the norm-referenced exam culture. The authors focus on innovations in one skill area of academic writing because 'achieving good composition is a complex and difficult task for both native speakers (NS) and non-native speakers of English (NNS)' (Cheung, 2016, p. 181). Understanding this complexity is important to effective teaching of writing.

For the definition of innovation, we adopted that offered by De Lano, Riley, and Crookes (1994, p. 489) as 'an informed change in an underlying philosophy of language teaching/learning, brought about by direct experience, research findings, or other means, resulting in an adaptation of pedagogic practices such that instruction is better able to promote language learning as it has come to be understood'. Our review may not focus exclusively on research that pioneers or tests the impact of actual changes or innovative programs, but also includes those that investigate existing practices to inform future changes. These research efforts are worth close attention from the academic world for the following reasons.

First, innovations in the English writing instruction in China are informed by the western second language writing theories. A critical review of China's practice could contribute to the understanding of the extent to which those theories can be applied to oriental contexts similar to that of China. This understanding can be fed back to the west and may foster the development of those theories. Second, innovations in China are extensive but far from exclusive. A critical review of the existing literature will inspire new ideas to inform future changes. Last, driven by the ever-increasing pace of globalization, English today has established its status as the lingua franca in key fields like business, education and technology. Leading by this trend, English instruction is gaining prominence in many parts of the world. China is without doubt not alone in striving for better instructional approaches. The innovations in the Chinese context may serve as reference to those who strive for the same. Since China in itself is a vast country with developmental gaps between regions, the review may provide useful reference within the Chinese context as well as contexts where English is used as a second/foreign language.

\section{MEthodology}

To guide our inquiry and selection of research articles, we formulated a research question: 
What are the innovations in English language writing instruction in China?

The studies were selected from the EBSCOhost database using 'China' and 'writing instruction' for key word search. There were initially over 900 articles generated. Given the large number, we narrowed down the list by restricting our focus on empirical studies published in SSCI journals (Table 1) over the past decade (i.e., during the period of 2005 2015). The number of articles was finalized to 56 after carefully reading the articles to eliminate duplicated studies and those without clear implication for innovation.

TABLE 1 .

JOURNALS REVIEWED

\begin{tabular}{|l|l|l|l|}
\hline 1 & Asia-Pacific Education Researcher & 15 & Journal of English for Academic Purposes \\
\hline 2 & Assessing Writing & 16 & Journal of Second Language Writing \\
\hline 3 & British Journal of Educational Technology & 17 & Language Awareness \\
\hline 4 & Computers \& Education & 18 & Language, Culture and Curriculum \\
\hline 5 & Educational Technology and Development & 19 & Language Learning and Technology \\
\hline 6 & Educational Technology \& Society & 20 & Language Teaching Research \\
\hline 7 & ELT Journal & 21 & ReCALL \\
\hline 8 & English for Specific Purposes & 22 & Studies in Educational Technology \\
\hline 9 & English in Australia & 23 & System \\
\hline 10 & English Teaching: Practice and Critique & 24 & The Canadian Modern Language Review \\
\hline 11 & Higher Education & 25 & TESOL Quarterly \\
\hline 12 & International Journal of Corpus Linguistics & 26 & The Journal of Experimental Education \\
\hline 13 & Journal of Computer Assisted Learning & 27 & World Englishes \\
\hline 14 & Journal of Education for Teaching & & \\
\hline
\end{tabular}

\section{RESULTS AND DISCUSSION}

As revealed in the selected articles, researchers have attempted to formulate an empirical understanding of Chinese students in order to provide insights into ways to inform new developments of writing instruction to meet their precise needs. The research has investigated a range of interrelated factors important to innovations in teaching writing.

\section{CORPUS-BASED APPROACHES ARE USEFUL IN ANALYZING STUDENTS' WRITING}

Studies examining writing features of Chinese students were mostly conducted through corpus-based approaches to analyze target textual features and identify trends in students' writing. For example, Chan (2010) analyzed learner writing at both secondary and university levels to investigate common lexico-grammatical errors. The study offered a taxonomy of errors which could help future teaching professionals anticipate learning problems at different proficiency levels where certain type of errors prevalent; develop remedial instructions targeting each type of errors; and also determine the priority of teaching according to error gravity. Huang (2015) looked into the use of lexical bundles by junior and senior year English majors and found that the frequency of their use increased during the course of university study but not accuracy. To increase accuracy, an adoption of the lexical approach and explicit instruction from both 'top-down' and 'bottom-up' (Flowerdew, 2009) may be needed. Li and Wharton (2012) explored the patterns of metadiscourse used by students at university level. The results showed that while the students are relatively well trained in the use of interactive resources, their repertoire of interactional resources is inadequate which may prevent them from writing in a preferable voice. Li and Wharton (2012) suggested that undergraduate writing instruction should emphasize more on interactional resources to equip students with the necessary knowledge. Besides the aforementioned corpus studies, Liardét (2013) investigated a much smaller sample of six pieces of writing by first and fourth year university students. The results show that the students managed to develop better control over the use of grammatical metaphor during their university years. However, the potential of grammatical metaphor for text organization and arguments building were still to be attained by students, which implies that targeted instruction of the functional use of grammatical metaphor should be emphasized in writing instruction to help students acquire the valued ways of meaning-making in the higher education setting.

STUDENTS' AFFECTIVE AND COGNITIVE FACTORS MAY INFLUENCE THE OUTCOME OF WRITING INSTRUCTION

While the studies reviewed above focused on the features of writing produced by Chinese students, the following studies explore students' affective and cognitive factors in the writing process that may influence the outcome of writing instruction. Concerning affective factors in the writing process, Yu and Lee (2015) found that students' motives directly influenced collaborative learning activities, such as peer review, in terms of peer stances, group interaction and subsequent revisions. Student motivation was found to be shaped by many factors including motivation for learning, previous experience with and personal beliefs of group work. So teachers should have a good understanding of their students and consider these factors when implementing collaborative learning activities. Lam and Law (2007) revealed that motivation mediates the effects of instruction on writing performance, particularly more motivating teaching strategies led to increased motivation in students and resulted in better writing performance. Motivating strategies identified in the study include providing challenging tasks; ensuring real-life significance in learning; stimulating students' curiosity; granting them more autonomy; recognizing their efforts; and offering useful feedback. These strategies tend to contribute to students' intrinsic motivation which correlates with long term success. However, due to 
the exam-oriented culture, the motivation of many Chinese students come from the pressure of getting good grades (Lam \& Lee, 2010), which is largely extrinsic and links to short term gains only. Thus the findings of this study are of particular relevance in the Chinese context for teachers to cultivate students' intrinsic motivation and help them achieve long term improvement. Woodrow (2011) identified self-efficacy and anxiety as two important variables in EFL writing. Unlike previous studies, the results of Woodrow's suggested that anxiety was not directly related to writing performance but mediated the effects of self-efficacy on writing performance. To enhance students' performance, writing teachers may attend to the contributors of self-efficacy and help students become more self-efficacious students.

When it comes to cognitive factors in the writing process, drawing on Activity Theory Lei (2008) explored writers' strategy use and identified four types of strategies, namely, artifact-mediated, rule-mediated, community-mediated, and role-mediated strategies. This conceptualization could be adopted to raise students' awareness of the available resources in facilitating their writing. Ong and Zhang (2013) examined the effects of strategy use and found that students adopting free-writing strategy outperformed those using planning or prolonged-planning strategies; while at the same time freewriting also led to more revisions on the final draft. The study showed that providing students with the content or organizational scheme could reduce their cognitive load and allow them to focus more on other aspects of writing. Patchwriting, which is often perceived to carry a negative connotation of plagiarism, was seen by Li and Casanave (2012) as an important writing strategy for undergraduate students. With limited knowledge of writing from sources, patchwriting is their strategic attempt to finished assignments on topics they still know little about. Instead of trying to detect and punish students for patchwriting, teachers should attend to students' writing difficulties and guide them through the process of learning appropriate textual borrowing. Ruan (2014) explored students' metacognitive awareness within the domain of cognitive writing theories using a three-fold framework - person, task, and strategy variables. Students' awareness of person variables include self-efficacy, anxiety and motivation; task variables consist of task purposes, constrains and cross-language task interpretation; strategy variables encompasses planning, text generating, revising and redrafting. As the interaction of these variables may affect the students' writing performance, the study suggested integrating systematic strategy instruction into the writing classroom to develop students' metacognitive awareness. In Ha and Storey's (2006) study, writing reflective journals before and after actual writing was found to be useful in enhancing students' metacognitive awareness for them to write better. The study demonstrated that peerediting activities enable students to activate their metacognitive awareness; transform what they know (declarative knowledge) into what they do (procedural knowledge); and improve their writing performance during the process. This lent support to peer feedback practices from the cognitive perspective of writing.

\section{TRAINING MAY HELP TEACHERS IMPROVE CONFIDENCE IN TEACHING WRITING}

While much previous writing research has been focused on the needs of students, inadequate attention was given to that of the teachers (Hirvela \& Belcher, 2007). Recently, the role of teachers as the key to the success of language instruction is increasingly recognized by both Chinese education administrators and teachers themselves. Motivated by this recognition, research into Chinese writing teachers surges for the purpose of seeking ways to improve their professional practices. Among them, the findings from Lee's (2010, 2011b) suggested that teachers' professional practices could be developed through teacher education, which was previously perceived by many to make little difference to the quality of teaching. The positive impact of teacher education include changing writing teachers' beliefs (Yang \& Gao, 2013) of their existing practices; developing their professional knowledge and skills; as well as enhancing their readiness for teaching writing (Lee, 2011b; Lee, 2013). Practical and practicable ways to promote teacher learning were also highlighted, namely critically reflecting and personalizing teaching theories, learning form research literatures, engaging in regular writing activities as well as developing writing teacher identity (Lee, 2010). However, there are challenges for teachers to apply what they learn from teacher education programs into their practice, such as conflicts between situated learning in the authentic classrooms and learning from teacher education programs; and issues of power and autonomy (Lee, 2011b). Further research should be carried out to find ways to support teachers in implementing changes in their practices and continuing their development as writing teachers. Despite the benefits of teacher education, teachers in many context still receive insufficient training on how to teach EFL writing (Hirvela \& Belcher, 2007). Among other constraints, their busy teaching schedules prevent them from reaching out to teacher education programs especially those located off-campus. To address the problem, Bai (2014) conducted a study on the possibility of helping teachers develop professionally in their own school context where they observe, discuss, and learn from each others' teaching with the help of a writing researcher. The result was positive as the teachers reported increased confidence in teaching writing after the program and they also felt that working in their own school context enable them to work out solutions specific to their own teaching situations thus can be immediately applied.

DIFFERENCES MAY APPEAR BETWEEN ASSESSMENT-ORIENTED TEACHER FEEDBACK AND NON-ASSESSMENT-ORIENTED TEACHER FEEDBACK

Most English language classrooms in China are teacher-centered where teachers stand for authority and their advice are often closely followed by students. Teacher feedback is also highly valued and perceived to be helpful in improving student writing. However, evidence from our selected research indicates that teacher feedback is not always as effective as expected. This section will examine these evidence and their implications on how to transform the current teacher feedback practices to better cater to the needs of students. 
Lee (2011c) explored teacher feedback in secondary schools and discovered that the majority of feedback (94\%) were directed on grammar due to teachers' belief that they were primarily teaching the language. Most of the feedback $(87 \%)$ also focused solely on accuracy and content, while neglecting other aspects of writing, such as organizational structure of the essay. However, writing competence means so much more than just grammatical accuracy. In higher education context, for example, grammar may not be valued much by subject teachers but the awareness and control of disciplinary writing conventions (Hyland, 2013). Thus, teacher feedback should have a balanced coverage of all important aspects of writing rather than on grammar only. Lee (2011c) also found that teachers were under the pressure of school policy to provide feedback on all errors in student writing. This kind of detailed error feedback was not positively received by students, especially those with lower proficiency, as they found it discouraging and difficult for them to adopt all the feedback in revision (Lee, 2008a). Even when students did adopt teacher feedback to revise, they sometimes did not understand the value and significance of the feedback because the teacher-centeredness involved in the process had made them passive and dependent students (Zhao, 2010). This calls for feedback activities where students can play a more active and autonomous role, such as conference with teachers, in-class discussions, and peer feedback (Lee, 2008a). To compound the problem, due to the influence of the single-draft classroom and the examination-oriented culture, teacher feedback in China mainly serve summative purpose, or assessment of learning (AOF), with an over-emphasis on the final product or the score (Lee, 2007). Once a score was given with no subsequent drafts required, students often would not bother to study and learn from the feedback, or make further revision (Lee, 2011c). This makes it necessary to promote the multiple drafts classroom where teacher feedback serves formative purpose, or assessment for learning (AFL), to de-emphasize score and promote learning. As indicated in Yu and Lee's (2013) study, where graduate supervisors' commentary practices were investigated and the non-assessment-oriented feedback provided by supervisors were found to stimulate more reading and thinking from the students, while also triggered more revision. Other factors such as the student engagement may also determine the effects of teacher feedback. Students' engagement was found to be attributed partly to their beliefs, experiences, learning goals, as well as the interactional context where feedback is provided (Han \& Hyland, 2015). So teachers need to have a good understanding of their students and carefully plan their feedback strategies. To sum up, the current teacher feedback practices are the result of an interplay among factors including teachers' values, belief, knowledge of assessment practices, and understanding of student needs (Lee, 2008b). These factors are subject to the influence of social and political issues related to power differentials and teacher autonomy. As a result, even though some teachers are cognitively aware of the need for changes of feedback practices, they may face obstacles and may need support through teacher training and empowerment by their school (Lee, 2011a).

\section{ASSESSMENT FOR LEARNING INFLUENCES STUDENT LEARNING OF WRITING}

The washback of writing assessment and how it translates into writing instruction has been an area of interest for researchers. For example, Green (2006) compared two courses preparing Chinese students for university study in the UK, with one course aimed primarily at IELTS preparation while the other served general English for Academic Purposes (EAP). The results showed that the IELTS preparation course covered a relatively limited range of skills due to its exclusive focus on the test, which may be effective in improving test score but insufficient in preparing students for their academic needs. The study suggests that writing instruction should look beyond the immediate demand of tests and address broader requirements of academic writing. Xu and $\mathrm{Wu}$ (2012) reported a bad distortion of the original intention of interpretational writing task in the Beijing Matriculation English Test (MET) for high-school students. The task was initially designed to encourage free expression of ideas so as to measure students' creative thinking. However, due to the high-stake nature of the MET, students tended to adopt the strategy of guessing the test-developer's intention and trying to figure out the 'best theme' in order to get a higher score. Over-emphasis on such test-taking strategy in writing instruction may prevent students from acquiring the target skills the test was designed to promote. This problem may arise due to the current norm-referenced exam culture in China where writing assessments mostly fall into the category of AOL to evaluate student learning and utilize scores for administrative and reporting purposes (Lee \& Coniam, 2013). While AOL has a role to play in the educational system, there is a growing emphasis on the implementation of AFL to improve teaching and promote learning. The above research on peer feedback, which is one form of AFL (Yu \& Lee, 2014), demonstrates a shifting focus from AOL to AFL in EFL writing. Research on teacher feedback (Lee, 2007) point to the importance of AFL in promoting the efficacy of teacher feedback. The remaining of this section will focus on studies documenting innovative efforts to bring AFL into the exam-oriented Chinese context.

Lee and Coniam (2013) demonstrated that AFL could be implemented through strengthening lesson planning and pre-assessment instruction; sharing learning goals with students to align assessment with instructional practice; as well as delivering diagnostic feedback using self-designed feedback forms to highlight the areas emphasized during class instruction. The majority of students became more positive about writing and their performance improved at the end of the study. Lee (2012) reported that genre can serve as an organizational principle to align instruction and assessment to make learning easier to students and teaching more systematic for teachers. Both students and teachers were positive with the genre-based AFL approach and found it conducive to both student learning and teacher development. Lam and Lee (2010) investigated and supported the formative potential of Portfolio Assessment (PA). The idea of PA is to evaluate students writing based on student achievements in progress rather than a single piece of work. The study demonstrated that PA had positive impacts on student motivation as it offered them autonomy in choosing their best 
work for grading and opportunities to enhance writing through conferences. PA also led to improvements in writing accuracy and the generation of more and better ideas. However, though positive about PA, students did not fully appreciate the absence of grades on interim drafts and still believed that grades motivated them. This again points to the importance of taking into consideration students' affective and cognitive factors in writing instruction.

INSTRUCTION MAY HELP WRITERS ACQUIRE SKILLS AND KNOWLEDGE OF WRITING FOR PUBLICATION

Chinese scholars face great pressure to get their research work published in peer-reviewed English journals with international prestige (Cargill, O'Connor, \& Li, 2012). In many Chinese universities, international publication has been made a graduation requirement for doctoral and some master's level students (Li, 2006). Catalyzed by this reality, there has been an increasing number of research investigating the process of writing for publication in the hope of providing practical recommendations for educating novice scholars. Cheung (2010) studied the first attempt by applied linguistics doctoral students to publish in refereed English journals. The study showed that students adopted various strategies to cope with difficulties in the process, among which seeking help from their dissertation supervisors was an important step. The study suggested that supervisors should integrate more writing activities with a real-world goal for publication into the mentoring process to give students impetus for their work. Moreover, incorporating a foundation course for publication into the PhD curriculums may stimulate the students and provide them with the necessary knowledge of publishing. Similar findings on the role of supervisors have been observed by Kwan (2010) who examined the extent to which instruction in research publication (IRP) is in place in Chinese universities. The results showed a general lack of systematic provision of IRP and that most formal IRP experienced by students are through mentoring by individual supervisors. The focus of the IRP tended to be more on the textual aspects of manuscripts which neglected other important aspects in the publishing process, such as the strategic conception of publishable research topics. Li (2006), after an investigation on novice writers' negotiation of knowledge contribution with multiple target discourse communities, also pointed out the need of EAP pedagogy to educate novices beyond the textual level and develop their understanding of the epistemological characteristics of particular disciplines. Beside pedagogical efforts to educate novice scholars, language professionals or proof readers also play an indispensable role in the international publication attempts of English as an Additional Language (EAL) writers (Burrough-Boenisch 2003). Li and Flowerdew (2007) found that Chinese mainland scientists normally turn to their supervisors, peers, and language professionals, who are EAL writers themselves, for assistance in editing the language of their work. Despite the convenience and benefits of seeking help from these language professionals, it is not without weakness. For example, they may not be familiar with the scientific register and research genres. Thus, the authors advocated more accessible professional editorial services; teaming-up of scientists and language professionals; and also efforts from academic journals to assist EAL writers in overcoming the language barrier. All of the studies reviewed above to some extent point out that the supervisors' expertise could serve as an importance source for educating novices in the Chinese context. This is consistent with the findings of $\mathrm{Li}$ (2012) who recognized the crucial role played by supervisors in the revision process, since supervisors sometimes did not explicitly explain to students the changes they made to the manuscripts. Consequently, students may not able to fully understand the rhetorical intentions behind the changes and may fail to learn from the process. Further research will be needed in how to effectively incorporate various sources into EAP instruction to teach the necessary skills and knowledge of international publication.

\section{TECHNOLOGY-ENABLED INSTRUCTION CAN HELP STUDENTS IN THEIR WRITING PROCESS}

The application of technology in educational context is no longer simply about adding visual and audio aids to make lessons more lively and attractive to students. With the rapid development of digital technology, second-generation web tools such as blogs and wikis are gradually showing their potential in creating an excellent collaborative environment to develop students' language skills in general, and writing skill in particular. Jones, Garralda, Li, and Lock (2006) compared the interactional dynamics of face-to-face and on-line peer-tutoring using various kinds of web tools for EFL writing. While face-to-face tutoring seemed better suited for discussion on grammar, vocabulary and style; online tutoring was shown to be more effective in addressing global issues such as content and writing process. Online interaction was also found to create a non-directive learning environment with less tutor control, which conforms more closely to the ideal symmetrical relationship advocated in the literature. The most researched web tool to assist collaborative learning in China is wikis. Mak and Coniam (2008) investigated authentic writing through wikis at secondary school level and found that students participating in a wiki-assisted collaborative program generated more texts with greater complexity and improved coherence. The program boosted students' confidence and developed their creative skills by providing them a real-life audience to impress. While extensive studies in and outside the Chinese context have shown that wikis can be an effective learning platform for students at both tertiary and secondary levels in different subject disciplines, the potential usage and effectiveness of wikis at primary school level is still in question considering the unique developmental and psychological dimensions of young students (Woo, Chu, \& Li, 2013). Some of our selected studies explored this issue and found that primary students' writing attitudes were significantly improved after the implementation of a wiki-based collaborative process writing pedagogy ( $\mathrm{Li}, \mathrm{Chu}, \& \mathrm{Ki}, 2014)$. Woo et al. (2013) observed three key affordances of wiki in the primary context, namely educational, social (collaborative), and technological affordance, which helped in scaffolding students and fostering their critical thinking and creative problem-solving skills. The participants in the study perceived the use of wiki to be enjoyable, beneficial to their 
collaboration, and helpful in better revising their writing. Their revisions covered the content, rather than language, because some features of the wiki tool such as 'spell check' could ease their cognitive load and allow them to pay more attention on content. The role of wikis in the revision process of primary school students was more closely investigated in a later study on peer feedback (Woo et al., 2013). The results of the study showed that peer comments posted via the wiki tool predominantly concerned the content and meaning level. Besides, more meaningful changes were made to address global writing issues rather than surface structures. The study also witnessed a significant improvement on students' group writing after the introduction of the wiki tool. Overall, the studies of wiki at the primary school support the benefits of wikis in EFL writing instruction among young students.

Other tools such as online corpus, automated writing evaluation program, and mobile devices have been researched to explore the possibility of applying them for pedagogical purposes. For online corpus, Hafner and Candlin's (2007) study showed that university students' attitude towards the use of an online concordancer to inform their legal writing is mixed. While some 'adopters' found it convenient and helpful, other 'non-adopters' tend to prefer other web tools such as Google or not to use any tool at all. Even for the 'adopters', there was no sign of them forming any long-lasting habits of corpus use. However, contrasting findings were observed in Huang's (2014) study where university English majors were generally positive with corpus and have made significant progress in the use of target lexico-grammatical patterns they learned through a paper-based corpus. The results of the two studies may suggest that corpuses are highly specialized language tools and they may be more helpful to inform language related aspects of writing such as lexicogrammatical patterns in Huang (2014), but fail to address other aspects of writing such as the legal content in Hafner and Candlin's (2007) study. Hence, it may be a better idea for students to access multiple web tools to inform different aspects of their writing. For automated writing evaluation programs, Wang, Harrington, and White (2012) compared the use of CTutor, which is designed to detect breakdowns in local coherence, to human raters in terms of the feedback they provide. The results demonstrated that CTutor achieved a relatively moderate accuracy in the detection of local breakdowns which was roughly similar to human rater performance. The feedback from CTutor led to similar revision patterns by student writers in comparison to those from human raters. This suggests that automated writing evaluation programs have the potential to inform student writing by delivering valid feedback for revision. The application of such tools may be of particular interest to Chinese teachers since the large class size in China make it difficult for them to give timely and detailed feedback to promote multiple drafts. In most cases, student writing is still taught and marked by local NNS teachers, who were shown to agree less with NS raters than CTutor in detecting local coherence breakdowns (Wang et al., 2012). For mobile devices, Hung and Young (2015) explored graduate students' use of 'ereaders', which refers to portable electronic devices such as the Amazon Kindle for reading digital materials, in facilitating process-based academic writing. The results showed that 'e-readers' were significantly beneficial to students' academic writing progress and those who adopted e-readers achieved better performance in their writing portfolio than those worked with printed-materials. Both students and teachers were positive about the use of e-readers as they provided a better environment for academic writing and functioned efficiently to assist the students' writing process as a portable library, a tool for annotation, a medium for immediate sharing and feedback with peers, and a practical storage for revised drafts.

The advancement of technology has led to changes in how we approach EFL writing instruction. English language competence in the digital age requires the ability to use the language for internet-mediated communication (Thorne $\&$ Black, 2007), which involves new genres, alternative modes of expression, as well as the challenges brought by a more diverse online audience. As a result, the goal of teaching and learning of writing should constitute the development of students' ability to assemble multiple modes in achieving successful communication in response for their target online audience. Hafner (2014) investigated multimodal assembles in a Chinese university where students in an English for science course engaged in a digital video project to report the findings of a scientific experiment. The results of the study showed that the project encouraged students to explore interesting modes of expression and provided them with opportunities for writing practice. While the participating students perceived multimodal semiotic resources to be useful in attracting the attention of their target audience on YouTube, they realized the challenges in combining multiple modes and the danger of overly-reliant on them. Their final works generally meet the challenge of writing in developing a rhetorical 'hook' and a proper discoursal identity through multimodal orchestration. The positive results of this study point to the possibility of embedding digital literacy in writing instruction in the Chinese context.

Besides direct intervention into pedagogy, the application of technology does facilitate effective research to inform the development of better writing instruction. Take wiki tools for example, apart from their benefits in serving as an useful tool to promote collaborative learning in the writing classroom, their tracking system can keep detailed records of the students' editing activities to offer an in-depth understanding of students' revision behavior (Woo et al., 2013). The automated writing evaluation system, which could improve students' writing by delivering valid feedback for revision (Wang et al., 2012), was found to be a useful research tool. It has been adopted in a nation-wide writing project (Jiang, 2015) to give a detailed and reliable description of Chinese university students' writing. The project uncovered meaningful trends and characteristics in the writings of Chinese students which could provide explicit guidance for students, teachers and curriculum developers. Furthermore, computer programs such as input logs and screen recorders have made the research into real-time writing process more convenient. Xu and Ding (2014) utilized two programs, Inputlog 4.0 and Camtasia 6.0, to examine writers' pausing patterns in a computer-assisted writing task. The results 
showed that skilled writers spent significant less time in prewriting stage, which is in contrast with previous findings about pen-and-paper writing, pointing to the necessity to attend to these differences in writing instruction. Skilled writers were found to pause longer and less frequently in prewriting to engage in global planning so that they could be more concentrated on text production in the composing stage. This implies the importance to teach the goals of each writing stage and how to effectively accomplish them. While skilled writers tend to search online for global ideas in their L1, less-skilled writers tend to search for L2 texts so that they can piece together for their own writing. This indicates that language proficiency is a great impediment in EFL writing, and even skilled writers in the study relied heavily on L1-L2 dictionaries. As the attention to linguistic problems may take up the much of the students' cognitive space, they would not be able to address global issues such as content and meaning. The study called for instruction to help students allocate their cognitive space to write more fluently and efficiently.

\section{NOVEL AND AUTHENTIC WRITING TASKS CAN PROMOTE STUDENTS' CRITICAL THINKING} ABILITY

Apart from trials with new technology, researchers have also examined how novel pedagogies could serve to enhance writing instruction and promote learning. For example, Lee and Wong (2014) reported a study on the implementation of a process-genre approach to writing in an EFL primary school, which is an under-explored area in EFL writing. The approach was significantly different from the traditional product approach. Its dual focus on writing process and genre knowledge was shown to be helpful to both strong and weak students in improving their motivation and writing performance. Also conducted in primary context, Lo and Hyland's (2007) study explored a new writing program aimed at enhancing students' motivation and engagement through introducing topics related to their life experiences with an genuine audience and a real-life goal to achieve. The program was found to be beneficial to students, especially those with lower achievements. However, while students' motivation and engagement improved, their language accuracy and organization scores fell. This may suggest a need for more scaffolding of language and organization strategies and a less daunting audience to begin with. The inclusion of genuine audience in writing instruction was also explored by Mak, Coniam, and Kwan (2008), who reported a trial scheme in which secondary students produced their own story books and shared them with students in nearby primary schools. While the primary readers showed great enjoyment and a desire to read more, the secondary writers were afforded the opportunity to explore a variety of genres, experience collaborative writing and peer support, improve their confidence, and boost their creativity which is often neglected in traditional pedagogy. Other studies tapping students' creativity include Burton (2010) and Dai (2010). Burton's study was based on secondary context where students participated in a Poetry for Pleasure project to experience creative writing. Mixed responses were collected from students concerning the writing of poetry in class. Students proficient in English enjoyed the social aspects involved in the project such as group work; those found English a barrier felt more pressured; and those managed to develop a real sense of creativity preferred individual writing outside the classroom on topics of their own choice. Despite the mixed responses, students generally enjoyed the poetry-based pedagogy and the sharing of ideas and self-produced work with their peers. Dai (2010) reported a creative writing course for university sophomores which incorporated methods from the west such as attending writing workshops and encouraging students to write about things that interest them and in ways that facilitate their self-expression. The course was shown to be effective in promoting students' critical thinking skills because writing was no longer presented as a tool for language learning, but also a creative enterprise for students to explore different aspects of their lives.

In higher education context, You and You (2013) explored the challenges faced by Chinese undergraduates when writing in subject content and possible strategies to facilitate their content learning. The students were found to be challenged by their limited vocabulary, unfamiliarity with discipline thinking, and lack of personal voice. Their professors developed various adaptive strategies to help them cope with the challenges, which include adjusting writing tasks to adopt more short essays; providing support for major writing assignments through workshops, group discussions, worksheets, and detailed feedback; and connecting subject content to students' own culture. These strategies shed light on how to teach English-medium content courses in the Chinese context, which is becoming increasingly in demand. Evans (2012) looked into the instructional potential of emails, which is widely used in business communications but has received scant attention in English for Specific Purposes instruction, to narrow the gulf that separates the office and the Business English classrooms. The data obtained from practicing business professionals and authentic emails messages offered pedagogically relevant information about the features and functions of business emails which were somehow divergent from the principles in textbooks. This point to the need for teachers and material developers to design tasks and materials that are informed by real-world evidence. This way we may fill the gap between writing instruction and what is demanded in real-life workplace.

\section{CONCLUSION}

As shown in the review above, some methods are 'easy' to use cross culturally: corpus-based approaches are useful in analyzing students' writing; assessment for learning influences student learning of writing; technology-enabled instruction can help students in their writing process; and authentic writing tasks can promote students' critical thinking ability.

The prevalence of the traditional product approach was arguably due to various contextual factors such as the normreferenced exam culture. To address the issue, a few studies called for the implementation of AFL to use assessment for 
promoting, rather than assessing students learning. As the shift from product to process approach is in line with the western pedagogical development and the AFL is essentially from the west, the innovations in China are shown to be prompted and informed by the western second language writing theories. Therefore, the understanding of how these approaches fit into the Chinese context could be fed back to the west for the refinement and development of these theories. The review also identified contributions by researchers to employ technology-enhanced strategies and novel pedagogy programs to enhance the quality of writing instruction, especially in promoting a desirable environment for student-centered collaborative learning. Overall, this paper contributes in providing a useful reference for teachers, researchers, and writing professionals in similar contexts on how to innovate their instructional practices. At the same time it may help identify learning gaps and future research directions.

\section{REFERENCES}

[1] Bai, B. (2014). Enhancing in-service teachers' professional learning through a school-based professional development programme in Hong Kong. Journal of Education for Teaching, 40(4), 434-36.

[2] Burrough-Boenisch, J. (2003). Shapers of published NNS research articles. Journal of Second Language Writing, 12, $223-43$.

[3] Burton, P. (2010). Creativity in Hong Kong schools. World Englishes, 29(4), 493-507.

[4] Cargill, M., O'Connor, P., \& Li, Y. (2012). Educating Chinese scientists to write for international journals: Addressing the divide between science and technology education and English language teaching. English for Specific Purposes, 31, 60-9.

[5] Chan, A. Y. W. (2010). Toward a taxonomy of written errors: Investigation into the written errors of Hong Kong Cantonese ESL learners. TESOL Quarterly, 44(2), 295-319.

[6] Cheung, Y. L. (2010). First publications in refereed English journals: Difficulties, coping strategies, and recommendations for student training. System, 38(1), 131-41.

[7] Cheung, Y. L. (2016). Teaching Writing. In W. A. Renandya, \& H. P. Widodo (Eds.), English Language Teaching Today: Building a Closer Link between Theory and Practice (pp. 179-194). Switzerland: Springer.

[8] Dai, F. (2010). English-language creative writing in mainland China. World Englishes, 29(4), 546-56.

[9] De Lano, L., Riley, L., \& Crookes, G. (1994). The meaning of innovation for ESL Teachers. System, 22(4), 487-90.

[10] Evans, S. (2012). Designing email tasks for the Business English classroom: Implications from a study of Hong Kong's key industries. English for Specific Purposes, 31, 202-12.

[11] Flowerdew, L. (2009). Applying corpus linguistics to pedagogy: A critical evaluation. International Journal of Corpus Linguistics, 14(3), 393-417.

[12] Gao, X., Liao, Y., \& Li, Y. (2014). Empirical studies on foreign language learning and teaching in China (2008-2011): A review of selected research. Language Teaching, 47(1), 56-79.

[13] Green, A. (2006). Washback to the learner: Learner and teacher perspectives on IELTS preparation course expectations and outcomes. Assessing Writing, 11, 113-34.

[14] Ha, H. W. M., \& Storey, P. (2006). Knowing and Doing in the ESL Writing Class. Language Awareness, 15(4), $283-300$.

[15] Hafner, C. A. (2014). Embedding digital literacies in English language teaching: Students' digital video projects as multimodal ensembles. TESOL Quarterly, 48(4), 655-85.

[16] Hafner, C. A., \& Candlin, C. N. (2007). Corpus tools as an affordance to learning in professional legal education. Journal of English for Academic Purposes, 6, 303-18.

[17] Han, Y., \& Hyland, F. (2015). Exploring learner engagement with written corrective feedback in a Chinese tertiary EFL classroom. Journal of Second Language Writing, 30, 31-44.

[18] Hirvela, A., \& Belcher, D. (2007). Writing scholars as teacher educators: Exploring writing teacher education. Journal of Second Language Writing, 16, 125-28.

[19] Hu, G. (2005). English language education in China: Policies, progress, and problems. Language Policy, 4(1), 5-24.

[20] Huang, K. (2015). More does not mean better: Frequency and accuracy analysis of lexical bundles in Chinese EFL learners' essay writing. System, 53, 13-23.

[21] Huang, Z. (2014). The effects of paper-based DDL on the acquisition of lexico-grammatical patterns in L2 writing. ReCALL, 26(2), 163-83.

[22] Hung, H.-C., \& Young, S. S.-C. (2015). The Effectiveness of Adopting E-Readers to Facilitate EFL Students' Process- Based Academic Writing. Educational Technology \& Society, 18(1), 250-63.

[23] Hyland, K. (2013). Student perceptions of hidden messages in teacher written feedback. Studies in Educational Evaluation, 39, 180-87.

[24] Jiang, Y. (2015). An automated essay-evaluation corpus of English as a Foreign Language writing. British Journal of Educational Technology, 46(5), 1109-17.

[25] Jones, R. H., Garralda, A., Li, D. C. S., \& Lock, G. (2006). Interactional dynamics in on-line and face-to-face peer-tutoring sessions for second language writers. Journal of Second Language Writing, 15, 1-23.

[26] Kwan, B. S. C. (2010). An investigation of instruction in research publishing offered in doctoral programs: the Hong Kong case. Higher Education, 59(1), 55-68.

[27] Lam, R., \& Lee, I. (2010). Balancing the dual functions of portfolio assessment. ELT Journal, 64(1), 54-64.

[28] Lam, S. F., \& Law, Y. K. (2007). The roles of instructional practices and motivation in writing performance. The Journal of Experimental Education, 75(2), 145-164.

[29] Lee, I. (2007). Feedback in Hong Kong secondary writing classrooms: Assessment for learning or assessment of learning? Assessing Writing, 12, 180-98.

[30] Lee, I. (2008a). Student reactions to teacher feedback in two Hong Kong secondary classrooms. Journal of Second Language Writing, 17(1), 144-64. 
[31] Lee, I. (2008b). Understanding teachers' written feedback practices in Hong Kong secondary classrooms. Journal of Second Language Writing, 17(2), 69-85.

[32] Lee, I. (2010). Writing teacher education and teacher learning: Testimonies of four EFL teachers. Journal of Second Language Writing, 19, 143-57.

[33] Lee, I. (2011a). Feedback revolution: what gets in the way? ELT Journal, 65(1), 1-12.

[34] Lee, I. (2011b). L2 Writing Teacher Education for In-service Teachers: Opportunities and Challenges. English in Australia, $46(1), 31-9$

[35] Lee, I. (2011c). Working smarter, not working harder: Revisiting teacher feedback in the L2 writing classroom. The Canadian Modern Language Review, 67(3), 377-99.

[36] Lee, I. (2012). Genre-based teaching and assessment in secondary English classrooms. English Teaching: Practice and Critique, 11(4), 120-34.

[37] Lee, I. (2013). Becoming a writing teacher: Using 'identity' as an analytic lens to understand EFL writing teachers' development. Journal of Second Language Writing, 22, 330-45.

[38] Lee, I., \& Coniam, D. (2013). Introducing assessment for learning for EFL writing in an assessment of learning examinationdriven system in Hong Kong. Journal of Second Language Writing, 22, 34-50.

[39] Lee, I., \& Wong, K. (2014). Bringing innovation to EFL writing: The case of a primary school in Hong Kong. The Asia-Pacific Education Researcher, 23(1), 159-63.

[40] Lei, X. (2008). Exploring a sociocultural approach to writing strategy research: Mediated actions in writing activities. Journal of Second Language Writing, 17, 217-36.

[41] Li, T., \& Wharton, S. (2012). Metadiscourse repertoire of L1 Mandarin undergraduates writing in English: A cross-contextual, cross-disciplinary study. Journal of English for Academic Purposes, 11, 345-56.

[42] Li, X., Chu, S. K. W., \& Ki, W. W. (2014). The effects of a wiki-based collaborative process writing pedagogy on writing ability and attitudes among upper primary school students in Mainland China. Computers \& Education, 77, 151-69.

[43] Li, Y. (2006). Negotiating knowledge contribution to multiple discourse communities: A doctoral student of computer science writing for publication. Journal of Second Language Writing, 15, 159-78.

[44] Li, Y. (2012). I have no time to find out where the sentences came from; I just rebuild them: A biochemistry professor eliminating novices' textual borrowing. Journal of Second Language Writing, 21, 59-70.

[45] Li, Y., \& Casanave, C. P. (2012). Two first-year students' strategies for writing from sources: Patchwriting or plagiarism? Journal of Second Language Writing, 21, 165-80.

[46] Li, Y., \& Flowerdew, J. (2007). Shaping Chinese novice scientists' manuscripts for publication. Journal of Second Language Writing, 16, 100-17.

[47] Liardét, C. L. (2013). An exploration of Chinese EFL learner's deployment of grammatical metaphor: Learning to make academically valued meanings. Journal of Second Language Writing, 22, 161-78.

[48] Lo, J., \& Hyland, F. (2007). Enhancing students' engagement and motivation in writing: The case of primary students in Hong Kong. Journal of Second Language Writing, 16, 219-37.

[49] Mak, B., \& Coniam, D. (2008). Using wikis to enhance and develop writing skills among secondary school students in Hong Kong. System, 36, 437-55.

[50] Mak, B., Coniam, D., \& Kwan, M. C. S. (2008). A buddy reading programme in Hong Kong schools. ELT Journal, 62(4), 38594.

[51] Ong, J., \& Zhang, L. J. (2013). Effects of the Manipulation of Cognitive Processes on EFL Writers' Text Quality. TESOL Quarterly, 47(2), 375-98.

[52] Ruan, Z. (2014). Metacognitive awareness of EFL student writers in a Chinese ELT context. Language Awareness, 23 , 76-90.

[53] Thorne, S. L., \& Black, R. W. (2007). Language and literacy development in computer-mediated contexts and communities. Annual Review of Applied Linguistics, 27, 133-60.

[54] Wang, Y., Harrington, M., \& White, P. (2012). Detecting breakdowns in local coherence in the writing of Chinese English learners. Journal of Computer Assisted Learning, 28, 396-410.

[55] Woo, M. M., Chu, S. K. W., \& Li, X. (2013). Peer-feedback and revision process in a wiki mediated collaborative writing. Educational Technology Research and Development, 61, 279-309.

[56] Woodrow, L. (2011). College English writing affect: Self-efficacy and anxiety. System, 39, 510-22.

[57] Xu, C., \& Ding, Y. (2014). An exporatory study of pauses in computer-assisted EFL writing. Language Learning and Technology, 18(3), 80-96.

[58] Xu, Y., \& Wu, Z. (2012). Test-taking strategies for a high-stakes writing test: An exploratory study of 12 Chinese EFL learners Assessing Writing, 17, 174-90.

[59] Yang, L., \& Gao, S. (2013). Beliefs and practices of Chinese university teachers in EFL writing instruction. Language, Culture and Curriculum, 26(2), 128-45.

[60] You, X., \& You, X. (2013). American content teachers' literacy brokerage in multilingual university classrooms. Journal of Second Language Writing, 22, 260-76.

[61] Yu, S., \& Lee, I. (2013). Understanding Supervisors' Commentary Practices in Doctoral Research Proposal Writing: A Hong Kong Study. The Asia-Pacific Education Researcher, 22(4), 473-83.

[62] Yu, S., \& Lee, I. (2015). Understanding EFL students' participation in group peer feedback of L2 writing: A case study from an activity theory perspective. Language Teaching Research, 19(5), 572-93.

Weiyu Zhang is Lecturer at the English Department of Shenzhen Open University. She received her MA in Applied Linguistics from National Institute of Education, Nanyang Technological University, Singapore. She has presented papers on second-language 
writing at prestigious conferences such as the American Association for Applied Linguistics Conference and the Symposium of Second Language Writing.

Yin Ling Cheung is Assistant Professor of English Language and Literature at National Institute of Education, Nanyang Technological University. She is also Head of Graduate Research and Academic Development Centre. Her research and teaching is second language writing. She co-edited Advances and Current Trends in Language Teacher Identity Research (Routledge, 2015) and co-authored English Style and Usage (Prentice Hall, 2011). She has published in journals such as System, The Asia-Pacific Education Researcher, and RELC Journal. 